Utah State University

DigitalCommons@USU

$9-24-2013$

\title{
Pulsed electro-acoustic (PEA) measurements of embedded charge distributions
}

JR Dennison

Utah State Univesity

Lee H. Pearson

Box Elder Innovations, LCC

Follow this and additional works at: https://digitalcommons.usu.edu/mp_conf

Part of the Physics Commons

\section{Recommended Citation}

J. R. Dennison ; Lee H. Pearson; Pulsed electro-acoustic (PEA) measurements of embedded charge distributions. Proc. SPIE 8876, Nanophotonics and Macrophotonics for Space Environments VII, 887612 (September 24, 2013); doi:10.1117/12.2025667.

This Article is brought to you for free and open access by the Materials Physics at DigitalCommons@USU. It has been accepted for inclusion in Conference Proceedings by an authorized administrator of DigitalCommons@USU. For more information, please contact digitalcommons@usu.edu.

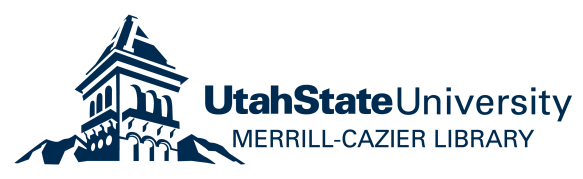




\title{
Pulsed Electro-Acoustic (PEA) measurements of embedded charge distributions
}

\author{
JR Dennison ${ }^{* a}$ and Lee H. Pearson ${ }^{\mathrm{b}}$ \\ ${ }^{a}$ Materials Physics Group, Physics Department, Utah State University \\ ${ }^{\mathrm{b}}$ Box Elder Innovations, LLC
}

\begin{abstract}
Knowledge of the spatial distribution and evolution of embedded charge in thin dielectric materials has important applications in semiconductor, high-power electronic device, high-voltage DC power cable insulation, high-energy and plasma physics apparatus, and spacecraft industries. Knowing how, where, and how much charge accumulates and how it redistributes and dissipates can predict destructive charging effects. Pulsed Electro-acoustic (PEA) measurementsand two closely related methods, Pressure Wave Propagation (PWP) and Laser Intensity Modulation (LIMM) nondestructively probe such internal charge distributions. We review the instrumentation, methods, theory and signal processing of simple PEA experiments, as well as the related PPW and LIMM methods. We emphasize system improvements required to achieve high spatial resolution for in vacuo measurements of thin dielectrics charged using electron beam injection.
\end{abstract}

Keywords: ultrasonics, charging, spacecharge, dielectrics, space environment, charge distributions, internal charging

\section{INTRODUCTION}

Knowledge of the spatial distribution and evolution of embedded charge in thin dielectric materials has important applications in semiconductor, high-power electronic device, and high-voltage DC power cable insulation industries ${ }^{1,2}$. Other key applications - including high energy physics facilities and plasma chambers and spacecraft charging - expose dielectrics to charged-particle fluxes. Charge is introduced into dielectric through electron beam injection, and can accumulate in dielectric materials until potentials are high enough to initiate electrostatic discharge (ESD). In space environments, spacecraft are exposed to charged particle fluxes ranging from relatively low $(<100 \mathrm{eV})$ to high $(>100 \mathrm{keV})$ energies at typical current densities ranging from $<0.1 \mathrm{pA} / \mathrm{cm}^{2}$ to $>10 \mathrm{nA} / \mathrm{cm}^{2}$ (see Fig. 1) ${ }^{4}$. Such spacecraft charging effects produce over half of the known spacecraft system anomalies - electron upsets, damage to components, power system debilities, and even complete satellite failures - that have been attributed to interactions with the natural space environment. ${ }^{3}$ As all of these applications proliferate-with the concomitant use of more advanced materials, more sensitive components, more severe environmental conditions, and more demanding objectives - the importance of understanding and minimizing dielectric charging will only become more important. In short, knowing how, where, and how much charge accumulates and how it redistributes and dissipates for given materials, configurations and environments is the key to prediction, avoidance and mitigation of these ubiquitous and destructive "arc and spark" effects.

The complex relationships between insulators and their surroundings are fundamentally based on a detailed knowledge of how individual materials store and transport charge ${ }^{3,5}$. The accumulation and re-emission of charge, and the rate that energy is imparted to the material depend on the energy distribution and magnitude of incident fluxes, as well as energy loss mechanisms of the incident particles for a given material ${ }^{6}$. The conductivity of high resistivity components (and its temperature dependence) is a key transport parameter to determine how the deposited charge will redistribute throughout a system, how rapidly charge imbalances will dissipate, and what equilibrium potential will be established under given environmental conditions? ${ }^{7}$. Thus, the electron emission and transport properties of materials are key parameters in determining the likelihood of deleterious charging effects.

However, while measurements of the electron emission and displacement currents, the evolving surface potential, and the electrostatic breakdown of materials exposed to particle fluxes have provided important information over the last five

JR.Dennison.USU.edu; phone 435-797-2936

Nanophotonics and Macrophotonics for Space Environments VII, edited by

Edward W. Taylor, David A. Cardimona, Proc. of SPIE Vol. 8876, 887612

(C) 2013 SPIE · CCC code: $0277-786 X / 13 / \$ 18 \cdot$ doi: $10.1117 / 12.2025667$ 


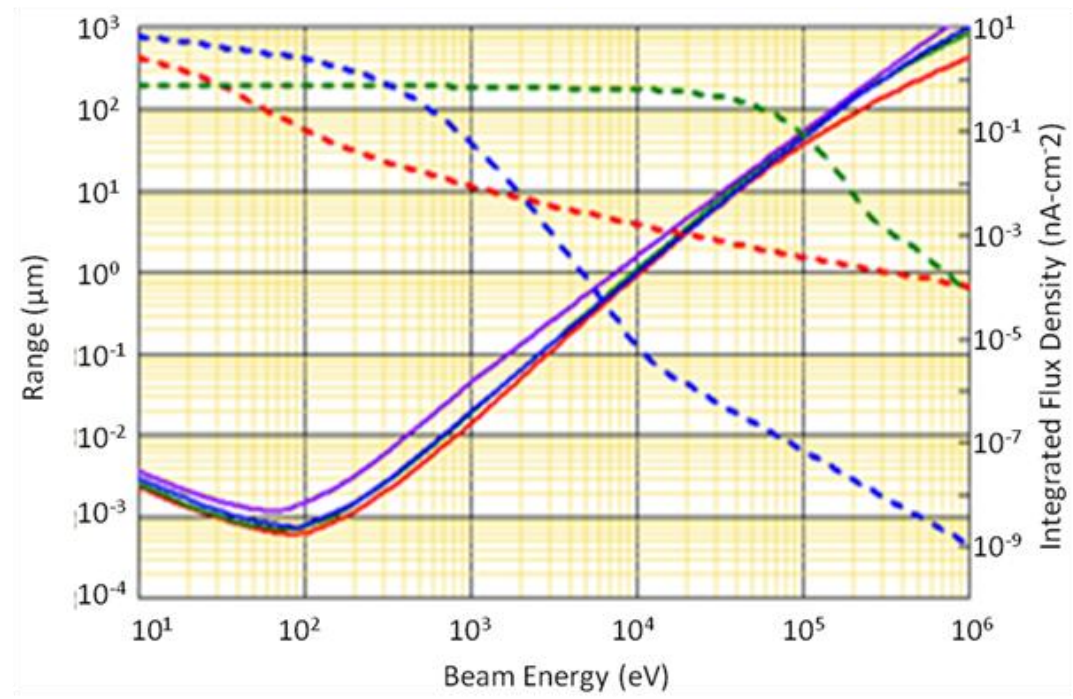

Figure. 1. Comparison of the energy dependence of representative space environment fluxes and penetration depths of common spacecraft materials. (i) (dashed curves - right axis) Integrated flux density of electrons impinging on a spacecraft surface in representative space environments as a function of the upper bound energy for: the solar wind (red); geosynchronous storm (green) and magnetosheath (blue) environments. ${ }^{3,8}$ (ii) (solid curves-left axis) Comparison of the electron range of common spacecraft materials as a function of incident energy based on the continuous slow down model of Wilson and Dennison: ${ }^{9}$ polyimide (Kapton) (red), polytetraflouroethylene (PTFE Teflon) (green), $\mathrm{SiO}_{2}\left(\mathrm{blue}_{\text {) }}\right.$ and $\mathrm{Al}_{2} \mathrm{O}_{3}$ (purple).

decades, the "holy grail" of materials characterization in dielectric charging is a nondestructive method to directly measure the magnitude and the spatial and temporal evolution of internal charge distributions on length and time scales appropriate to practical charging problems. Pulsed Electro-acoustic (PEA) measurements-and two closely related methods, Pressure Wave Propagation (PWP) and Laser Intensity Modulation (LIMM) — provide such methods.

\section{COMPARISON OF METHODS}

This paper provides an overview of these three methods, with an emphasis on use of these techniques for high spatial resolution in vасио measurements of thin film polymeric, ceramic, or glass dielectric materials charged with medium to high energy $\left(\sim 10^{3} \mathrm{eV}\right.$ to $\left.\sim 10^{7} \mathrm{eV}\right)$ electron beams. A description of each of these methods is summarized in Table 1, along with a list of their relative advantages and disadvantages. Conceptual instrument diagrams for the PEA, ${ }^{10}$ PWP, ${ }^{11}$ and LIMM ${ }^{12}$ methods configurations are shown in Figure 2. All three systems consist of a thin film sample bounded by two electrodes: (i) a probe electrode that introduces a high-frequency pulsed waveform (high-voltage electric field waveform for PEA, ultrasonic acoustic waveform for PWP, and optically-induced thermal acoustic waveform for LIMM) and (ii) a sensor electrode that measures an amplified high-frequency response signal (ultrasonic acoustic waveforms for PEA or displacement current waveforms for PWP and LIMM, converted to voltage signals and amplified). The primary instrumentation components for the three methods are identified in Table 2.

\subsection{Design Criteria}

We begin first by considering the general requirements for such a nondestructive method to measure the spatial and temporal evolution of internal charge distributions. The design criteria are established by charging applications, especially for electron flux charge deposition for spacecraft charging. What has been missing to date, particularly for the spacecraft charging community, is the resolution needed to measure charge distributions on a length scale typically encountered in real spacecraft charging situations. The required spatial resolution is set by requirements that either:

- For many common spacecraft applications a reasonable lower bound of thickness is set by thin thermal blankets, solar coverglasses, or thermal paints with thickness on the order of 0.5mil $(\sim 12 \mu \mathrm{m})$ (See Table 3)

- The penetration depth for lower energy electrons that are most prevalent in space environment fluxes $(\sim 1$ to 50 $\mathrm{keV}$ ). 
Table 1. Relative advantages and disadvantages of charge density distribution measurement methods.

\begin{tabular}{|c|c|c|c|}
\hline Method & Description & Advantages & Disadvantages \\
\hline PEA & $\begin{array}{l}\text { Pulsed Electro-acoustic }{ }^{10} \\
\text { - Voltage applied across charged dielectric } \\
\text { creates pressure wave detected by } \\
\text { piezoelectric transducer. }\end{array}$ & $\begin{array}{l}\text { - Nondestructive. } \\
\text { - Low cost. } \\
\text { - Simplified modeling. } \\
\text { - High resolution. }\end{array}$ & $\begin{array}{l}\text { - Limited instrumentation } \\
\text { bandwidth } \\
\text { - Limitations and cost of } \\
\text { available high-voltage, high- } \\
\text { frequency amplifiers. }\end{array}$ \\
\hline PWP & $\begin{array}{l}\text { Pressure Wave Pulse } \\
\text { Pressure wave created by: } \\
\text { - (PIPWP) Piezoelectric-induced pressure } \\
\text { wave pulse Excitation with piezoelectric } \\
\text { transducer. } \\
\text { - (LIPP) Laser-induced pressure wave } \\
\text { propagation. Pulsed laser-induced } \\
\text { pressure-wave from thermo-elastic effect } \\
\text { creates pressure wave that passes through } \\
\text { charge layer and induces a voltage (or } \\
\text { current) across dielectric layer. }\end{array}$ & $\begin{array}{l}\text { - Nondestructive. } \\
\text { - Can be modeled } \\
\text { (slightly more } \\
\text { complex than PEA). } \\
\text { - High resolution. } \\
\text { - Best results with step- } \\
\text { function pressure } \\
\text { wave. } \\
\text { - Lower voltage } \\
(<300 \mathrm{~V}) \text { required. }\end{array}$ & $\begin{array}{l}\text { - PIPWP has lower probe } \\
\text { frequency. } \\
\text { - LIPP method may damage } \\
\text { material sample. } \\
\text { - Laser (LIPP) is best method } \\
\text { for inducing step function } \\
\text { pressure wave, but has high } \\
\text { implementation costs. }\end{array}$ \\
\hline LIMM & $\begin{array}{l}\text { Laser Intensity Modulation Method }{ }^{12} \\
\text { - Thermal wave induced by modulating laser } \\
\text { intensity, which acts on embedded charge. }\end{array}$ & $\begin{array}{l}\text { - High spatial } \\
\text { resolution. } \\
\text { - No high-voltage, } \\
\text { high-frequency } \\
\text { amplifier required }\end{array}$ & $\begin{array}{l}\text { - Modeling more difficult. } \\
\text { - Dispersion of thermal pulse } \\
\text { limits effective probe depth. } \\
\text { - May have high } \\
\text { implementation costs. }\end{array}$ \\
\hline
\end{tabular}

Referring to Table 3 and Figure 1, it is evident that spatial resolutions of $\lesssim 1 \mu \mathrm{m}$ are required to satisfy both criteria (i) and (ii) to adequately resolve charge distributions for incident lower energy electrons with the highest fluxes for all but the thinnest spacecraft materials. Therefore, the targeted spatial resolution is specified at $\lesssim 1 \mu \mathrm{m}$ (see Table 3 ).

The temporal resolution needed to acquire measurements is set by a reasonable fraction of:

- The time to acquire substantial charge in the space environment $\left(\sim 10^{1}\right.$ to $10^{3} \mathrm{sec}$ or longer in typical space environments to acquire charge densities of magnitude $\lesssim 1 \mathrm{nC} / \mathrm{cm}^{2}$ resulting in electric fields $\lesssim 10^{6} \mathrm{~V} / \mathrm{m}$ for $\sim 100 \mu \mathrm{m}$ thick dielectric layers) or

- The time to dissipate charge through the material $\left(\sim 10^{0}-10^{4} \mathrm{sec}\right.$ or higher; see Table 3$)$, as limited by the conductivity of typical spacecraft dielectrics $\left[\sim 10^{-13}\right.$ to $\left.10^{-17}(\Omega-\mathrm{cm})^{-1}\right]$.

Together, this suggests a range of $1 \mathrm{~s}$ to $10^{3} \mathrm{~s}$ time resolution. As noted below, existing PEA systems can routinely acquire data on time scales of $<1 \mathrm{~s}$, in special cases down to $\sim 10 \mu \mathrm{s}{ }^{10,16}$. Therefore, the targeted temporal resolution is specified at $\lesssim 1 \mathrm{sec}$.

A reasonable target for charge sensitivity is $\lesssim 1 \mathrm{nC} / \mathrm{cm}^{2}$, equal to $1 \%$ of breakdown field strength with charge layer near midpoint of thinnest $(\sim 10 \mu \mathrm{m})$ dielectric spacecraft films with a relative permittivity of $\sim 2$ (see Table 3). PEA apparatus are now routinely used to measures charge distributions of densities $\gtrsim 100 \mathrm{nC} / \mathrm{cm}^{3}$ or $\sim 10^{12}$ electrons/ $/ \mathrm{cm}^{3}$ (that is, $\gtrsim 0.1 \mathrm{nC} / \mathrm{cm}^{2}$ for $\sim 10 \mu \mathrm{m}$ thick samples) ${ }^{14,16}$.

A reasonable target for the maximum voltage applied across test samples is set by considering that:

- To avoid electrical breakdown across samples, the electric field should not exceed $\sim 100 \mathrm{MV} / \mathrm{m}$, or about $\sim 1 \mathrm{kV}$ across a $10 \mu \mathrm{m}$ thick sample and $\sim 100 \mathrm{kV}$ across a $1 \mathrm{~mm}$ sample. 
(a)

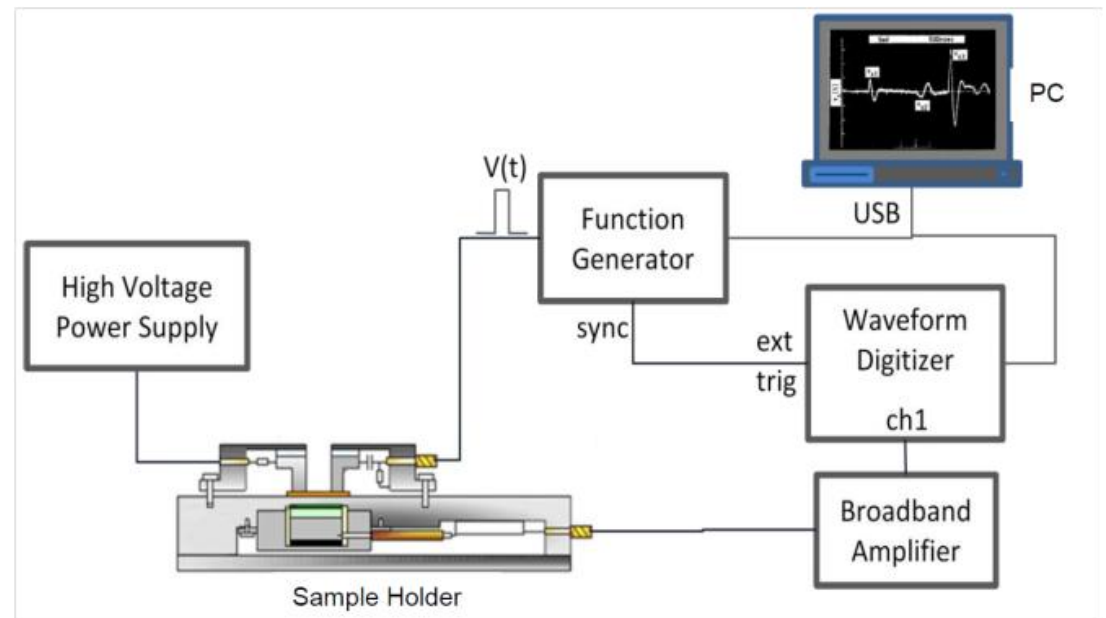

(b)

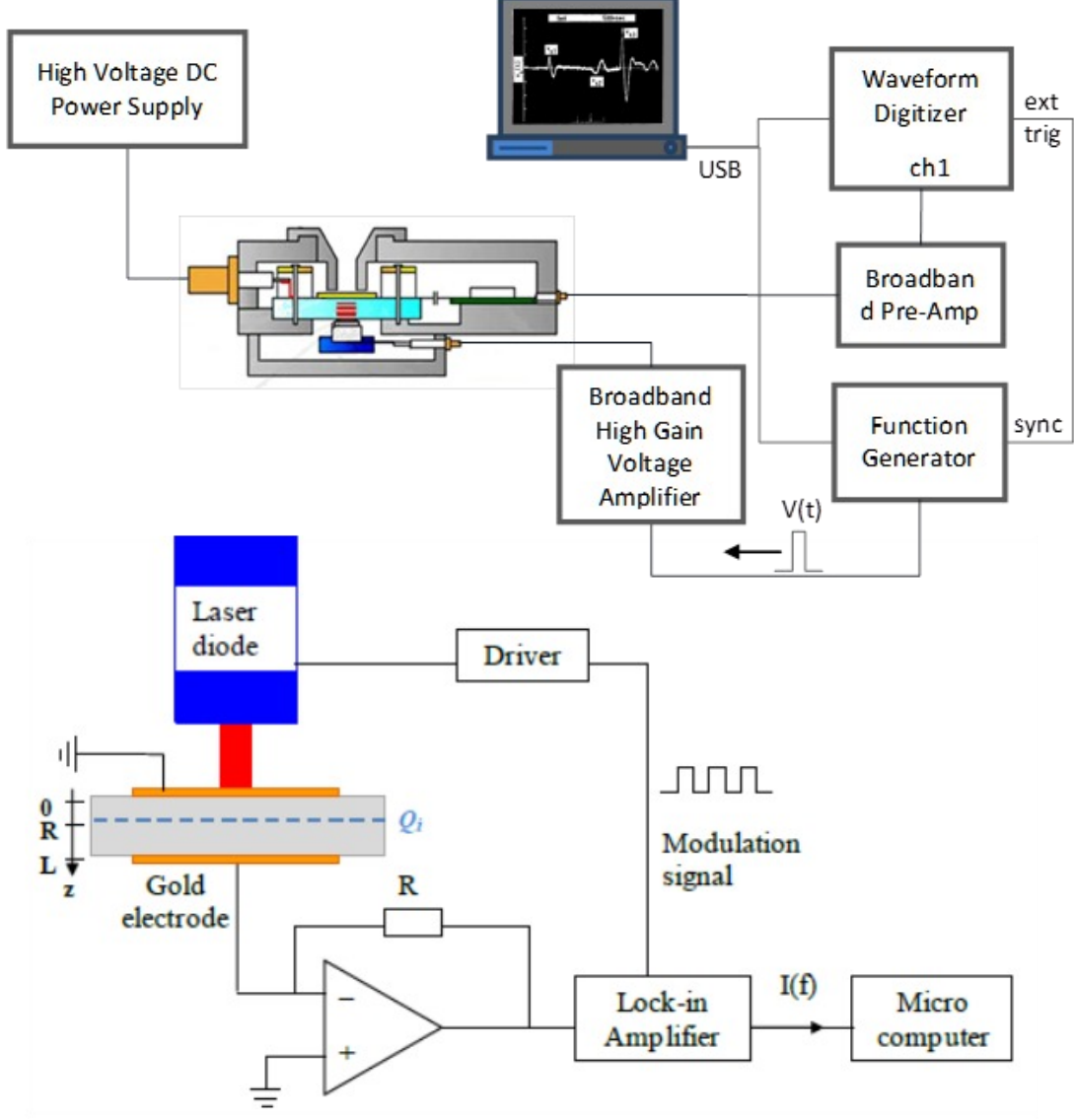

Figure 2. Conceptual diagram showing system instrumentation components for: (a) PEA method; (b) PWP method; (c) LIMM sensor configuration (after Ref. 12).

Table 2. System Component Requirements

\begin{tabular}{|l|c|c|c|c|c|c|c|c||}
\hline Method & $\begin{array}{c}\text { HV } \\
\text { Supply }\end{array}$ & $\begin{array}{c}\text { High- } \\
\text { gain HV } \\
\text { Amp }\end{array}$ & $\begin{array}{c}\text { Pre- } \\
\text { Amp }\end{array}$ & $\begin{array}{c}\text { Function } \\
\text { Generator }\end{array}$ & $\begin{array}{c}\text { Waveform } \\
\text { Digitizer }\end{array}$ & $\begin{array}{c}\text { Ultrasonic } \\
\text { Transducer }\end{array}$ & $\begin{array}{c}\text { Lock-In } \\
\text { Amp }\end{array}$ & $\begin{array}{c}\text { Laser \& } \\
\text { Driver }\end{array}$ \\
\hline PEA & $\mathrm{X}$ & $\mathrm{X}$ & $\mathrm{X}$ & $\mathrm{X}$ & $\mathrm{X}$ & Pulser & -- & -- \\
\hline PPW & $\mathrm{X}$ & -- & $\mathrm{X}$ & $\mathrm{X}$ & $\mathrm{X}$ & Receiver & -- & -- \\
\hline LIMM & $\mathrm{X}$ & -- & $\mathrm{X}$ & $\mathrm{X}$ & $\mathrm{X}$ & Receiver & $\mathrm{X}$ & $\mathrm{X}$ \\
\hline
\end{tabular}


Table 3. Typical Thin Film Dielectric Materials Charging Parameters.

\begin{tabular}{|c|c|c|c|c|c|}
\hline Application & $\begin{array}{c}\text { Typical } \\
\text { Materials } \\
\end{array}$ & $\begin{array}{c}\text { Thickness } \\
(\mu \mathrm{m})\end{array}$ & $\begin{array}{c}\text { Penetration } \\
\text { Energy }^{\mathrm{a}}(\mathrm{eV}) \\
\end{array}$ & $\begin{array}{c}\text { Conductivity } \\
(\Omega-c m)^{-1}\end{array}$ & $\begin{array}{c}\text { Charge Decay } \\
\text { Time }^{c}(\mathbf{s}) \\
\end{array}$ \\
\hline $\begin{array}{l}\text { Bulk Insulators, } \\
\text { Optical Elements }\end{array}$ & 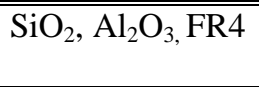 & $10^{2}--10^{4}$ & $5 \cdot 10^{4}--2 \cdot 10^{6}$ & $10^{-14}-10^{-17}$ & $10^{1}--10^{4}$ \\
\hline Thermal Paints & $\mathrm{ZnO}, \mathrm{C}$ & $10^{1}--10^{3}$ & $1 \cdot 10^{4}--2 \cdot 10^{5}$ & $10^{-13}-10^{-17}$ & $10^{0}--10^{4}$ \\
\hline Solar Coverglass & $\mathrm{SiO}_{2}, \mathrm{MgF}, \mathrm{Al}_{2} \mathrm{O}_{3}$ & $10^{1}--10^{2}$ & $2 \cdot 10^{4}--5 \cdot 10^{4}$ & $10^{-12}-10^{-18}$ & $10^{0}--10^{6}$ \\
\hline Thermal Blankets & PI, PTFE, PET & $10^{1}--10^{2}$ & $1 \cdot 10^{4}--8 \cdot 10^{4}$ & $10^{-17}-10^{-19}$ & $10^{4}--10^{6}$ \\
\hline Composite Layers & Organics, Epoxy & $10^{-1}--10^{2}$ & $5 \cdot 10^{2}--5 \cdot 10^{4}$ & $10^{-14}-10^{-18}$ & $10^{1}--10^{5}$ \\
\hline Optical Coatings & $\mathrm{SiO}_{2}, \mathrm{MgF}$ & $10^{-1}--10^{0}$ & $1 \cdot 10^{3}--1 \cdot 10^{4}$ & $10^{-14}-10^{-17}$ & $10^{1}--10^{4}$ \\
\hline Contamination Layers & $\begin{array}{l}\text { Oxides, Organics } \\
\text { Silicone, a-C }\end{array}$ & $10^{-3}--10^{0}$ & $1 \cdot 10^{2-}-3 \cdot 10^{3}$ & $10^{-12}-10^{-18}$ & $10^{0}--10^{6}$ \\
\hline
\end{tabular}

a Energy required for electron beam to penetrate half way through material, based on electron range models of Wilson and Dennison. ${ }^{9}$

${ }^{\mathrm{b}}$ See, for example, Dennison, et al. ${ }^{13}$

${ }^{c}$ Based on simple planar capacitor model of materials layers, with $\tau=\epsilon_{0} / \sigma$. See, for example, Roth and Dennison. ${ }^{7}$

- Surface potentials in the space environment and under electron beam charging can at most reach the incident electron energy. Above $\sim 10^{2} \mathrm{keV}$, the flux in even the most severe space environments is usually a fraction of lower energy fluxes (see Fig. 1).

- Arcing and $\mathrm{x}$ ray generation by electron guns are more problematic above $\sim 20 \mathrm{kV}$ to $50 \mathrm{kV}$.

Together, these considerations suggest a reasonable upper bound on applied voltages of $\sim 10 \mathrm{kV}$ to $\sim 20 \mathrm{kV}$. It is wise to include the capability to monitor surface potential during sample irradiation to insure that breakdown potentials are not exceeded. The upper bound on practical applied voltages provides another motivation for higher resolution PEA; the electric fields sustainable by new extreme insulators with electrostatic breakdown field strengths of $\gtrsim 10^{9} \mathrm{~V} / \mathrm{m}$ can only be realized at this applied voltage upper bound for film of $\lesssim 10 \mu \mathrm{m}$ thickness. [ICSD O3A:4]

Space test chambers should be combatible with thin film polymeric, ceramic, or glass dielectric samples such as those listed in Table 3. Operating temperatures in space ranges from $\$ 40 \mathrm{~K}$ to $>350 \mathrm{~K}$ (or much higher in rare, extreme cases). Ideally, the test chambers should operate at vacuums of $10^{-4} \mathrm{~Pa}$ to $10^{-7} \mathrm{~Pa}$ as is encountered in the space environment; at a minimum the chambers need to operate well below the Paschen disharge curve peak near $10^{-1} \mathrm{~Pa}$ and below $10^{-3} \mathrm{~Pa}$ to avoid reduced lifetimes for the filaments producing the electron beams for deposition.

\subsection{Pulsed electro-acoustic (PEA) Method}

Pulsed electro-acoustic (PEA) measurements are arguably the most promising method for many of the applications indentified here. ${ }^{14,15}$ PEA techniques generate acoustic waves within the material by applying high-voltage, highfrequency pulsed voltage probe waveforms to stimulate motion of the internal charges bound to atoms in a solid through Coulombic forces. The acoustic signal generated by the atomic displacement propagates through the material and is then converted to an electrical response signal using adjacent piezoelectric transducers.

PEA apparatus are now routinely used to measures charge distributions of density ( $\gtrsim 100 \mathrm{nC} / \mathrm{cm}^{3}$ or $\sim 10^{12}$ electrons $/ \mathrm{cm}^{3}$, that is $\gtrsim 1 \mathrm{nC} / \mathrm{cm}^{2}$ for $\sim 100 \mu \mathrm{m}$ thick samples) with dynamic resolution $\lesssim 1 \mathrm{~s}^{14,16}$. However, achieving the necessary spatial resolution for many applications involving electron beam injection has proven to be the critical problem for investigations using PEA methods over the last three decades ${ }^{14,16,17}$. Initial PEA studies ${ }^{10,18,19,20}$ had spatial resolutions of $\sim 100 \mu \mathrm{m}$, sufficient to study larger amplitude charge distributions in $\sim 1 \mathrm{~mm}$ thick samples implanted with $>200 \mathrm{keV}$ electron beams. In the subsequent three decades, improvements the basic method by Maeno ${ }^{10}$-including detection electronics sensitivity and speed, better piezo-transducers, and increased ultrasonic frequencies-have led to contemporary PEA resolution of $\lesssim 10 \mu \mathrm{m}^{10,21-24}$ The best systems have depth resolutions of $\sim 4 \mu \mathrm{m}{ }^{14,16}$. In a recent article, Arnaout $e t$ al. reviewed progress made in improving the spatial resolution of the PEA method and concluded that it was necessary to address "each part of the [PEA] cell: electrical component[s], signal treatment, choice of electrode material and sensor, etc," including (i) the transducer/sensor/cell materials, geometry and thickness and (ii) the modeling 
of the acoustic wave generation and propagation in the complex media. ${ }^{14}$ This is an active area of research currently being addressed by many groups.

An important enhancement has been the development of "open PEA" or "short-circuit PEA" systems that provide direct access to thin film samples for electron beam irradiation, a significant improvement in simulating electron beam injection applications in laboratory tests ${ }^{24-26}$. Initial open PEA systems used very thin metallic electrodes deposited on the surface, which were limited to higher energy electron beams that could penetrate the metallic electrodes ${ }^{24}$. A more recent method uses a noncontact electrode placed $\sim 1 \mathrm{~mm}$ above the dielectric surface, which can be swung out of the way during electron beam deposition ${ }^{26}$. This has the disadvantages that signal amplitude decreases with increasing electrode-to-sample distance and the enhanced possibility of arcing from the sample to electrode, especially at elevated charge densities ${ }^{16}$. Some open PEA systems are designed to operate in high vacuum, which is required for low energy $\left(\lesssim 10^{5} \mathrm{eV}\right)$ studies of materials charging.

Griseri has reviewed the current status of different modified PEA apparatus with specific extended test capabilities ${ }^{16}$. These include:

- Systems with high probe pulse repetition rates of 2-10 kHz capable of measuring charge profiles every 10-20 $\mu \mathrm{s}$ have been developed to study fast propagation of charge distributions through more conductive systems and charge dynamics during electrostatic breakdown ${ }^{27,28}$. Faster high voltage amplifier electronics and waveform digitizers are the key technologies that have enabled such advanced systems.

- Systems developed particularly for use in the high voltage cable industry are capable of tests at up to $550 \mathrm{kV}^{29-33}$.

- Systems have been developed to study the lateral distribution and evolution of charges in the electrode plane, with lateral resolution on the order of $\sim 100 \mu \mathrm{m}$ to $\sim 1000 \mu \mathrm{m}$. These alternately used movable electrodes ${ }^{34}$, arrays of probe or sensor electrodes ${ }^{35}$, or acoustic lenses ${ }^{36}$.

- Standard PEA systems in thermally controlled enclosures can operate from $\sim 180 \mathrm{~K}^{37}$ to $\sim 340 \mathrm{~K}$ at up to $85 \%$ humidity ${ }^{38,39}$. Higher sample temperatures, up to $\sim 520 \mathrm{~K}$, have been achieved with additional cooling of system components ${ }^{40}$.

- Semi-transparent conducting Al electrodes have been used for systems that study internal charge distributions induced by penetrating light and the subsequent in situ evolution of the charge distributions due to photoconduction 41,42 . These photoconductivity studies have obvious parallels to the penetrating electron beams injections and radiation induced conductivity studies focused on in this article.

\subsection{Pressure Wave Propagation (PWP) Method}

A variation of the PEA apparatus has been developed, called "pressure wave propagation" (PWP) ${ }^{43-45}$. This method is, basically, the reverse of the PEA process. An acoustic pressure wave is generated by an ultrasonic transducer, which propagates into the charged dielectric film, and "jogs" the atomic layers and their attached charge distributions. This, in turn, causes a change in the induced charge on the electrodes on each side of the dielectric film. This change in charge (or displacement current) can be measured as a current amplified response signal. The piezoelectric-induced pressure wave pulse (PIPWP) method uses excitation with an ultrasonic (piezoelectric) transducer to generate the pressure wave. The laser-induced pressure wave propagation (LIPP) method uses a pulsed laser-induced pressure-wave created through a thermo-elastic effect to generate the pressure wave that passes through charge layer and induces a voltage (or current) across dielectric layer. An open PPW system has been developed ${ }^{43-45}$, as a modification of the open PEA apparatus of Miyake ${ }^{25}$.

One advantage of this method is that the very high-voltage $(\$ 5 \mathrm{kV})$, high-frequency amplifiers used in the standard PEA method are not required for PWP. The high-frequency voltage waveforms needed to drive the ultrasonic sensor can be $\lesssim 100-400 \mathrm{~V}$. This minimizes the possibility of an electric discharge ${ }^{43}$ in the chamber for in vacuo measurements. The PIPWP has an inherent limit in spatial resolution due to the lower probe frequency of the ultrasonic pulser, as compared with a voltage (PEA) or light (LIMM) probe pulse. Under certain circumstances, the high intensity laser pulse needed to generate an intense enough thermal pulse for detection with LIPP can cause radiation damage in the sample. The high intensity, short-pulsed lasers used with LIPP can be costly and difficult to incorporate into a PPW system, especially an open PWP system in a vacuum chamber. 


\subsection{Laser Intensity Modulation Method (LIMM)}

The Laser Intensity Modulation Method (LIMM) method ${ }^{12,46}$ uses a non-uniform thermal gradient in the bulk produced by irradiating the sample surface with an intensity modulated laser diode as the probe waveform. This creates a thermal wave that acts on the embedded charge, which creates a pyroelectric displacement current. This is very similar to the way the PWP pressure wave generates a displacement current due to the piezoelectric effect. The pyroelectric current depends on the laser beam modulation frequency, sensor temperature, and sample structure and physical properties; it also depends on the internal space charge and polarization of the sample. A low-noise preamplifier converts the current response signal into a voltage signal that is fed to a lock-in amplifier [see Figure 2(c)].

A low voltage signal is used with a higher current driver in the LIMM to provide the laser diode pulses. As with the PWP, no high-voltage, high-frequency amplifier is required for the LIMM. This minimizes the possibility of an electric discharge across the signal electrode or in the chamber for in vacuo measurements. ${ }^{12}$

LIMM requires a thin electrode on the beam side of the sample (at least in present configurations), and so is not strictly an "open" method. ${ }^{12}$

LIMM has potential for very high spatial resolution, on the order of $\sim 1 \mu \mathrm{m}$, but is much more surface sensitive due to the optical/thermal excitation method. Dispersion of the thermal pulse limits the effective probe depth, thereby restricting higher resolution measurements to thin samples ${ }^{18}$. Also, this method would tend to modify the temperature of the charged dielectric film. Detailed modeling of the propagation of the thermal pulse in the sample is required; this makes accurate modeling substantially more difficult ${ }^{12}$.

\section{SYSTEM DETAILS}

We continue with a discussion of some specific system design details, including those for system components, the sample stack and piezoelectric transducers, and signal processing.

\subsection{System Components}

A high-voltage, low-noise DC power supply is used to apply potential across the sample to produce an electric field to drive charge transport and to polarize samples to acquire reference waveforms. As noted above, a $10 \mathrm{kV}$ supply is sufficient to apply $10 \mathrm{MV} / \mathrm{m}$ field ( 10\% of typical breakdown field strength) across $\sim 10^{3} \mu \mathrm{m}$ thick samples (see Table $3)$.

An arbitrary waveform generator is used to produce excitation pulses for all three methods. The pulse width needs to be much less than the transit time of the acoustic wave from the charge layer to the boundary of the dielectric film, ( $\$ 2 \mathrm{~ns}$ for a lower bound $10 \mu \mathrm{m}$ thick sample). Compatibility with the high frequency ultrasonic pulses, as set by the system impedance and sample capacitance, requires a bandwidth $>1 \mathrm{GHz}$, with a square wave rise time $\lesssim 2 \mathrm{~ns}$. A low voltage signal is used with a driver in the LIMM to provide the laser diode pulses. For PWP methods, low voltage waveformson the order of 200-400 V-are needed to drive the piezoelectric ultrasonic pulser. For PEA methods, the low voltage waveform needs to be amplified using a high-frequency, high-gain, high-voltage amplifier. Output voltages up to $\sim 5 \mathrm{kV}$ are typically required to generate sufficient response signal.

Data acquisition is done with either a waveform digitizer or a digital storage oscilloscope. An acquisition rate $>1 \mathrm{GHz}$ is required to capture the pulsing and response signals at the $>200 \mathrm{MHz}$ rate of the ultrasonics. Typical waveforms have $>10 \mathrm{k} \mathrm{pts} /$ waveform with $>8$ bits amplitude resolution to capture an adequate time duration and frequency range with sufficient dynamic range. The LIMM also requires a modest quality lock-in amplifier to extract the harmonics of the input waveform from the output capacitive signal coupled through a high-gain, >1 GHz high-frequency pre-amplifier.

\subsection{Sample/Sensor Stack}

Figure 3 shows the arrangement of the layers comprising the sample stack in a typical PEA system. Typical PEA systems use samples [(4) in Fig. 3] with $\sim 0.5 \mathrm{~cm} 2$ to $\sim 5 \mathrm{~cm} 2$ surface areas and $\lesssim 0.1 \mathrm{nC}$ to $\lesssim 2 \mathrm{nC}$ capacitances. The high ratio of lateral to thickness dimensions allows the analysis be treated as 1D propagation in typical systems The sample high voltage bias and capacitively-coupled lower voltage probe electrical pulse are applied to the upper surface of the sample by an upper conducting electrode [(5) in Fig. 3]. A semi-conductor film is often inserted between the upper electrode and the sample [between (4) and (5) in Fig. 3] to provide better acoustic impedance matching. 


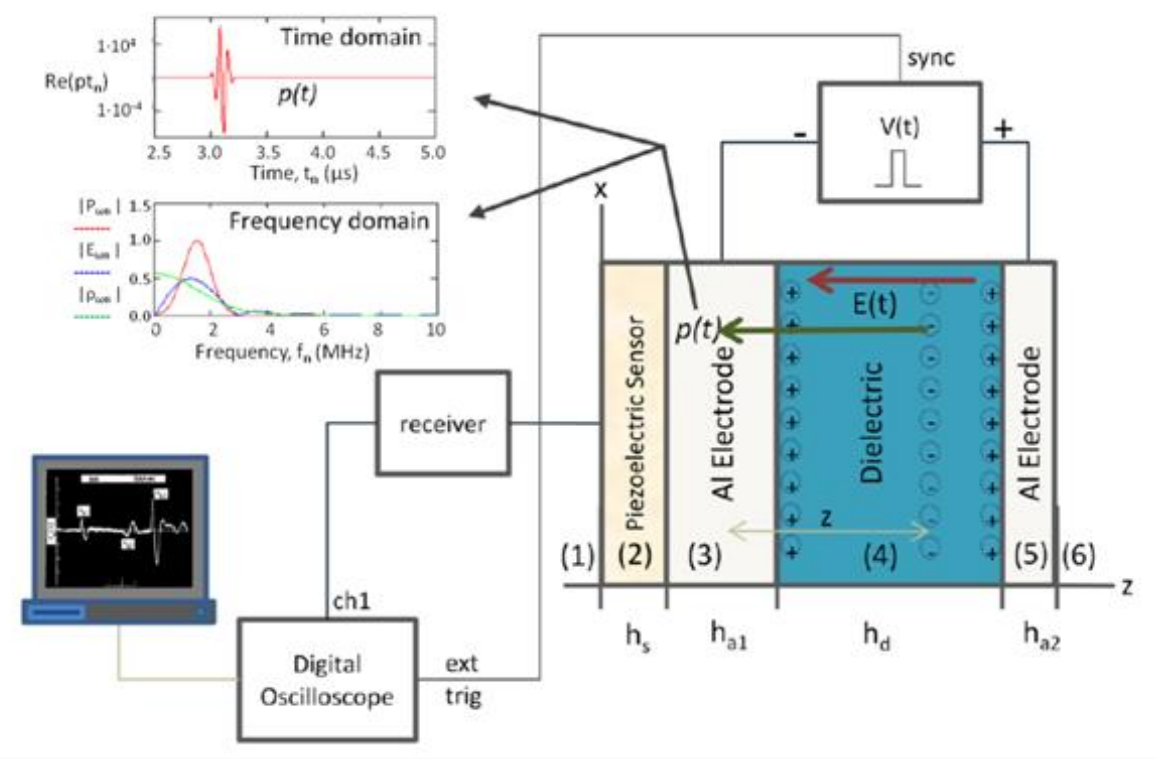

Figure 3. Conceptual diagram showing a typical PEA setup with a sample stack (including charged dielectric film, electrodes, sensor, and absorber) and basic equipment components.

A grounded rear (lower) electrode [(3) in Fig. 3] sets the system ground and confines the electric field applied to the sample. The acoustic wave generated in the sample propagates through the sample and the lower electrode with the velocity of sound to the piezoelectric acoustic sensor [(2) in Fig. 3]. A typical $1 \mathrm{~cm}$ thick Al lower electrode provides $\sim 2$ $\mu$ s delay, which is used to temporally separate the acoustic signal from the electrostatic noise originating with the pulse generator. An absorber [(1) in Fig. 3] is positioned under the piezoelectric sensor to dampen the acoustic signal reflected from the sensor absorber interface.

\subsection{Ultrasonic Sensor/Transducer}

The piezoelectric sensor converts the acoustic signal to an electrical signal, which is amplified by an in situ preamplifier. For high resolution mesurements, the piezoelectric sensor needs to have a center frequency of $\sim 200 \mathrm{MHz}$ with a bandwidth $>200 \mathrm{MHz}$. The resolution depends on the transmission quality at the sample. Galloy et al. identified the acoustic detector and its coupling to the surrounding elements of the sample stack as "the key of the PEA method." ${ }^{47}$ They have modeled the acoustic and electrical properties of the piezoelectric transducer using the Mason-Redwood model ${ }^{48,49}$, with an eye to improving the signal processing by better mapping the acoustic impedance matching of the system ${ }^{47}$.

The most common choice for piezoelectric sensor material is polyvinylidene fluoride (PVDF) ${ }^{16,25,43}$. This material offers the advantage of being very broadband in its response. It is readily purchased in very thin ( $4 \mu \mathrm{m}$ to $52 \mu \mathrm{m})$ sheets, that can be prepared in any desired shape and size. Thin metallic electrodes are typically deposited directly on the PVDF films. Currently, the highest resolutions reported are between $\sim 5 \mu \mathrm{m}$ and $10 \mu \mathrm{m}$ with $9 \mu \mathrm{m}$ PVDF ${ }^{25,43}$ and $\sim 3 \mu \mathrm{m}$ resolution with $4 \mu \mathrm{m} \mathrm{PVDF}^{16,50}$. In order to improve charge distribution spatial resolution to $\leq 1 \mu \mathrm{m}$, use of $\sim 1 \mu \mathrm{m}$ PVDF is being considered. Even though signal amplitude is reduced by using very thin PVDF films, improved resolution has been reported with PVDF sensors with $1 \mu \mathrm{m}$ thickness ${ }^{14}$. Reduced signal amplitude can be compensated for by increasing the sensor sensitivity. Use of alternate polymeric nanocomposite piezoelectric sensor/actuator materials may lead to higher sensitivity and better spatial resolution ${ }^{51,52}$. These materials exhibit higher polarization and enhanced piezoelectric behavior similar to the standard PVDF thin-film bulk materials used in most systems.

\subsection{Signal Processing}

Work by Maeno ${ }^{5}$ provides a detailed basis for modeling PEA experiments. Bernstein ${ }^{53}$ and Arnaout et al. ${ }^{54}$ present more recent analyses of PEA modeling. The analysis of the acoustic signal essentially use a time of flight analysis of the propagation of a complex acoustic waveform through the media. There is an extensive literature, but most models can 
be classified as ray-tracing models ${ }^{11,12,14,15,18,19,23,43}$. That is, dominant and first arriving wavelets are individually traced through the sample and adjacent material layers in the sample holder and then mathematically summed (assuming the principal of linear superposition) to give a complete waveform that is equivalent to the measured waveform. Most literature models only account for the initial wavelet generated by the charge layer in the dielectric and ignore multiply reflecting wavelets. Waveform analysis uses the system response to a static polarization field with no induced charge to determine a system response function. The effects of the charge distribution and the response function are decoupled by binning the charge distributions in spatial regions and transforming the signals into frequency space, deconvoluting the signals, and performing an inverse Fourier transform ${ }^{16,54,54}$. Limited filtering, including bandpass and Gaussian filters, is often used to improve the signal quality. Determination of the best methods for signal processing is an ongoing problem ${ }^{16,54}$.

The detailed theory for the PWP method is given by Gerhard-Multhaupt ${ }^{45}$. PWP theory is, basically, the reverse of the PEA theory. Similar signal processing issues apply.

\section{CONCLUSION}

Pulsed Electro-acoustic (PEA) measurements - and two closely related methods, Pressure Wave Propagation (PWP) and Laser Intensity Modulation (LIMM) - are well-established nondestructive methods to probe the spatial and temporal evolution of internal charge distributions in dielectric materials. Work is underway to improve the method to extend its range of applications for samples as thin as $10 \mu \mathrm{m}$ with spatial resolutions of $\lesssim 1 \mu \mathrm{m}$, profile acquisition rates of $<1 \mathrm{~s}$ and charge distribution sensitivities $\gtrsim 100 \mathrm{nC} / \mathrm{cm}^{3}$ (that is, $\gtrsim 0.1 \mathrm{nC} / \mathrm{cm}^{2}$ for $\sim 10 \mu \mathrm{m}$ thick samples). These capabilitiesalong with the ability to develop open sensor geometries, high vacuum compatibility, and a range of operating temperatures - will open the door to myriad new applications of PEA measurements, including electron beam charge deposition found in spacecraft charging and for high-energy and plasma physics apparatus. The prospect for meeting these objectives has been outlined and appears to be within reach in the near future.

\section{ACKNOWLEDGMENTS}

We gratefully acknowledge contributions of students in the USU Materials Physics Group, including Kristina Sorenson, Kent Hartley, Justin Dekany, and Robert Johnson. Tim Doyle of Utah Valley University provided key assistance with ultrasonic measurements. This work was supported by a project through Phase I and II STTR projects sponsored by the Air Force Research Laboratory (AFRL).

\section{REFERENCES}

[1] Liu, R., Takada T., Takasu N., "Pulsed electroacoustic method for measurement of charge distribution in power cables under both DC and AC electric fields", Phys. D: Appl. Phys. vol. 26, p. 986-993, (1993).

[2] Piovan, U., "Insulation systems for HVDC transformers: present configurations, trends, challenges, solutions and open points," 2013 IEEE International Conference on Solid Dielectrics (ICSD), Bologna, Italy, July, (2013).

[3] Hastings, D., and Garrett, H., [Spacecraft Environment Interactions], New York, NY: Cambridge Press, (1996).

[4] Leach, R. D., and Alexander, M. B., Failures and anomalies attributed to spacecraft charging, NASA Reference Publication 1375, NASA Marshall Space Flight Center, August (1995).

[5] Dennison, J. R., Hoffmann, R. C., and Abbott, J., "Triggering Threshold Spacecraft Charging with Changes in Electron Emission from Materials," Paper AIAA-2007-1098, Proc. of $45^{\text {th }}$ AIAA Meeting on Aerospace Sci., Reno, NV, (2007).

[6] Wilson, G., Evans, A., Dekany, J. and Dennison, J. R., "Charging Effects of Multilayered Dielectric Spacecraft Materials: Surface Voltage, Discharge and Arcing," IEEE Trans. on Plasma Sci., (2013), in press.

[7] Roth, J. A., Hoffmann, R. C., Dennison, J. R., and Tippetts, J. R., "Effects of Radiation Induced Conductivity on Electrostatic Discharge in Insulating Materials," Paper Number: AIAA-2009-3527, Proc. of $1^{\text {st }}$ AIAA Atmospheric and Space Environments Conf., (2009). 
[8] Minow, J., Parker, L. N., Alstaff, R. L., Blackwell Jr., W. C. and Dickmann, A. "Radiation and Internal Charging Environments for Thin Dielectrics in Interplanetary Space," Proc. $9^{\text {th }}$ Spacecraft Charging Techn. Conf., (Epochal Tsukuba, Tsukuba, Japan, April, (2005).

[9] Wilson, G. and Dennison, J. R., "Approximation of Range in Materials as a Function of Incident Electron Energy," submitted to IEEE Trans. on Plasma Sci., (2011).

[10] Maeno, T. et. al., "Measurement of Spatial Charge Distribution in Thick Dielectrics Using the Pulsed Electroacoustic Method," IEEE Trans. Electrical Insulation, 23(3):433, (1988).

[11] Takada, T. et. al., "Comparison between the PEA Method and the PWP Method for Space Charge Measurement in Solid Dielectrics," IEEE Trans. On Dielectrics and Electrical Ins., 5(6):944, (1998).

[12] Griseri, V., Bouchareb, S., Berquez, L., "Adaptation of the LIMM Technique Data Treatment to Perform Measurements in Vacuum," 2012 IEEE Conference on Electrical Insulation and Dielectric Phenomena (CEIDP), (Montreal, Quebec, Canada, October, (2012).

[13] Dennison, J. R., Frederickson, A. R., Green, N. W., Benson, C. E., Brunson, J. and Swaminanthan, P., "Materials Database of Resistivities of Spacecraft Materials.," NASA Space Environments and Effects Program, (2003). Published electronically as part of the Charge Collector Knowledgebase $3^{\text {rd }}$ Ed. at http://see.msfc.nasa.gov/scck/

[14] Arnaout, M., Berquez, L., Baudoin, F., and Payan, D. "Contribution to Improving the Spatial Resolution of a Pulsed Electro Acoustic Cell Measurement," IEEE Int. Conf. Solid Dielectrics, Germany, (2010).

[15] Griseri, V. et al., "Pulsed Electro-acoustic Technique Applied to In-situ Measurement of Charge Distribution in Electron-irradiated Polymers," IEEE Trans. Dielectrics and Electrical Insulation, 11(5):891, (2004).

[16] Grisseri, V., "Pulsed Electroacuotsic Method," Dielectric Materials for Electrical Engineering, pp. 229-250, (2010).

[17] Laurent, C., "Charge dynamics in polymeric materials and its relation to electrical ageing," 2012 IEEE Conference on Electrical Insulation and Dielectric Phenomena (CEIDP), Montreal, Quebec, Canada, October 14-17, (2012).

[18] Laurenceau, P., Dreyfus, G. and Lewiner, J., "New Principle for the Determination of Potential in Dielectrics," Phys. Rev. Lett. 38(1):46, (1977).

[19] Sessler, G. M., West, J. E., Berkley, D. A. and Morgenster, G., "Determination of Spatial Distribution of Charges in Thin Dielectrics," Phys. Rev. Lett. 38(7):368, (1977).

[20] Takada, T., Maeno, T. and H. Kushibe, "An Electric Stress-Pulse Technique for The Measurement of Charges in a Plastic Plate Irradiated by an Electron Beam,” IEEE Trans. Electrical Insulation, vol. EI-22, no. 4, p. 497-501, (1987).

[21] Maeno, T., Fukunaga, K. and Takada, T., "High Resolution PEA Charge Distribution Measurement System," (1994).

[22] Boudou, L. et. al., "Effect of Temperature on Space Charge Formation in Low Density Polyethylene-Role of Antioxidant," 2004 International Conference on Solid Dielectrics, Toulouse, France, July, (2004).

[23] Gallot-Lavallée, O., Griseri, V., Teyssedre, G. and Laurent, C., "The pulsed electro-acoustic technique in research on dielectrics for electrical engineering: Today's achievements and perspectives for the future," $R S-R I G E$. 8(56):749, (2005).

[24] Griseri, V. et. al., "Space-Charge Detection and Behavior Analysis in Electron-irradiated Polymers," IEEE Trans. Plasma Sci., 34(5):2185, (2006).

[25] Miyake, H., Numata, S., Tanaka, Y. and Takada, T., "Characteristic of Internal Charge Distribution in PI Irradiated by Proton," $10^{\text {th }}$ Spacecraft Charging Tech. Conf., Albuquerque, NM, (2010).

[26] Imai, S., Tanaka, Y., Fukao, T. Takada, T. and Maeno, T., "Development of new PEA system using open upper electrode", Proceedings CEIDP'04, IEEE, p. 61-64, July (2004).

[27] Matsui, K, Tanaka, Y., Fukao, T., Takada, T. and Maeno, T., "Short-duration space charge observation in LOPE at the electrical breakdown", Proceedings IEEE CEIDP'02, p. 598-601, (2002).

[28] Fukuma,. M., Maeno, T., Fukunaga, K. and Nagao, M., "High repetition rate PEA system for in-situ space charge measurements during breakdown tests", IEEE Trans. DEI, vol. 11, no. 1, p. 155-159, (2004).

[29] Fu, M., Chen, G., Davies, A.E., Tanaka, Y. and Takada, T., "A modified PEA space charge measuring system for power cables", Proceedings 6"' ICPADM'OO, p. 104-107, June (2000).

[30] Fukunaga, K., Miyata, H., Sugimori, M. and Takaoa, T., "Measurement of charge distribution in the insulation of cables using the pulse electro-acoustic method", Trans. IEE Japan, vol. IIO-A, no. 9, p. 647-648, (1990).

[31] Fu, M. and Chen, G., "Space charge measurement in polymers insulated power cables using flat ground electrode PEA system", IEE Proc.-Sci Meas. Technol., vol. 150, no. 2, March (2003). 
[32] Hozumi, N., Suzuki, H., Okamoto, T., Watanabe, K. and Watanabe, A., "Direct observation of time-dependent space charge profiles in XLPE cable under high electric' fields", IEEE Trans. Die!. EI, vol. I, no. 6, p. 1068-1076, (1994).

[33] Hozumi, N., Takeda, T. Suzuki, H. and Okamoto, T., "Space charge behavior in XLPE cable insulation under 0.2$1.2 \mathrm{mV} / \mathrm{cm}$ DC fields", IEEE Trans. Diel EI, vol. 5, no. I, p. 82-90, (1998).

[34] Lmaisumi, Y., Suzuki, K., Tanaka, Y. and Takada, T., "Three-dimensional space charge distribution measurement in solid dielectrics using pulsed Electroacoustic Method", Proceedings IEEE ISEIM'95, p. 315-318, (1995).

[35] Tanabe, Y., Fukuma, M., Minoda, A. and Nagao, M, "Multi-sensor space charge measurement system on PEA method", Proceedings IEE Jpn. CFM'03, no. 7-14, (2003).

[36] Maeno, T., "Three-dimensional PEA charge measurement system", IEEE Trans. DEI, vol. 8, no. 5, p. 845-848, (2001).

[37] Murakami, Y., Fukuma, M., Hozumi, N. and Nagao, M., "Space charge measurement in EVA film at cryogenicroom temperature region", Trans. IEE Jpn.; vol. 121-A, no. 8, p. 758-763, (2001) (in Japanese).

[38] Kltejima, M., Tanaka, Y. and Takada, T.,"Measurement of space charge distribution at high temperature using the pulsed electro acoustic method", Proceedings 7"' Int. Conf. DMMA '96, p. 8-11, Bath, UK, September (1996).

[39] Gallot-Lavallée, O., Griseri, V., Teyssedre, G. and Laurent, C., "The pulsed electro-acoustic technique in research on dielectrics for electrical engineering: Today's achievements and perspectives for the future," $R S-R I G E$. 8(56):749, (2005).

[40] Miyauchi, H., Fukuma, M., Muramoto, Y., Nagao, M. and Maeno, T., "Space charge measurement system under high temperature on PEA method", Proceedings IEE Jpn. CFM'03, no. 7-14, (2003).

[41] Tanaka, A., Maeda, M. and Takada, T., "Observation of charge behavior in organic photoconductor using pressurewave propagation method", IEEE Trans. on Electric. Insulat., vol. 27, no. 3, p. 440-444, June (1992).

[42] Satoh, Y., Tanaka, Y. and Takada, T., "Observation of charge behavior in organic photoconductor using the pulsed electroacoustic method and Pressure wave propagation Method", Proceedings 1EE 7th Int. Conf DMMA '96, p. 112115, September (1996).

[43] Takada, T., Miyake, H. and Tanaka, Y., "Pulse Acoustic Technology for Measurement of Charge Distribution in Dielectric Materials for Spacecraft," IEEE Transactions on Plasma Science, 34(5):2176, (2006).

[44] Takada, T. et. al., "Comparison between the PEA Method and the PWP Method for Space Charge Measurement in Solid Dielectrics," IEEE Trans. On Dielectrics and Electrical Ins., 5(6):944, (1998).

[45] Gerhard-Multhaupt, R., "Analysis of Pressure-Wave Methods for the Nondestructive Determination of Spatial Charge or Field Distributions in Dielectrics," Physical Review B, 27(4):2494, (1983).

[46] Bouchareb, S., Griseri, V. and Berquez, L., "In situ space charge profile measurements on electronic irradiated material by LIMM," 2013 IEEE International Conference on Solid Dielectrics, Bologna, Italy, July (2013)

[47] Galloy, L., Berquez, L., Baudoin, F. and Payan, D., "PSpice modeling of the Acoustic Detector for a Pulsed ElectroAcoustic Cell," 2013 IEEE International Conference on Solid Dielectrics, Bologna, Italy, July (2013)

[48] Mason, W. P., "An Electromechanical Representation of a Piezoelectric Crystal Used as a Transducer," Proceedings of the Institute of Radio Engineers, vol. 23, no. 10, p. 1252- 1263, (1935).

[49] Redwood, M., "Transient Performance of a Piezoelectric Transducer," J. Acoustical Society of America, vol. 33, no. 4, p. 527-536, (1961).

[50] Maeno, T. and Fukunaga, K., "High-Resolution PEA Charge Distribution Measurement System," IEEE Transactions on Dielectrics and Electrical Insulation, 3(6):754, Dec. (1996).

[51] Batth, A., Mueller, A., Rakesh, L., and Mellinger, A., "Electrical Properties of Poly(Vinylidene FluorideHexafluoropropylene) (PVDF-HFP) Blended with Carbon Nanotubes," 2012 IEEE Conference on Electrical Insulation and Dielectric Phenomena (CEIDP), (Montreal, Quebec, Canada, October (2012).

[52] Kim, G., Hong, S. M. and Seo, Y., "Piezoelectric properties of poly(vinylidene fluoride) and carbon nanotube blends: $\beta$-phase development." Phys. Chem. Chem. Phys., vol. 11, pp. 10506-10512, (2009).

[53] Bernstein, J. B., "Analysis of the electrically stimulated acoustic-wave method for observing space charge in semiinsulating films," Phys. Rev. B, vol. 44, no. 19, p. 10804-10814, Nov. (1991).

[54] Arnaout, M., Paulmier, T. and Dirasen B., Berquez, L., Baudoin, F. and Payan, D., "Description and experimental validation of a new PEA signal processing concept," 2013 IEEE International Conference on Solid Dielectrics, Bologna, Italy, June (2013). 